\title{
Update on the clinical use of the low-molecular- weight heparin, parnaparin
}

\author{
This article was published in the following Dove Press journal: \\ Vascular Health and Risk Management \\ 24 September 2009 \\ Number of times this article has been viewed
}

\section{Giuseppe Camporese' \\ Enrico Bernardi ${ }^{2}$ \\ Franco Noventa ${ }^{3}$ \\ 'Unit of Angiology and ${ }^{3}$ Department of Clinical and Experimental \\ Medicine, Clinical Epidemiology Group, University Hospital of Padua, Italy; ${ }^{2}$ Department of Emergency and Accident Medicine, Hospital of Conegliano Veneto, Italy}

\begin{abstract}
Parnaparin is a low-molecular-weight heparin that has widely shown its efficacy and safety in prevention of venous thromboembolism, in the treatment of chronic venous disorders, and in the treatment of venous and arterial (stable and unstable angina, acute ST-segment elevation myocardial infarction) thrombosis. Parnaparin at the respective dosages of 3200, 4250, 6400, or $12800 \mathrm{IUaXa}$ for a period ranging from 3 to 5 days to 6 months, is usually administered subcutaneously by means of once-daily regimen and is better tolerated than unfractionated heparin at the injection site. In the variety of commercially available low-molecular-weight heparins, parnaparin represents a useful therapeutic option, even though little evidence is available comparing the superiority or the equivalent efficacy and safety of parnaparin to that of the unfractionated heparin or placebo. This review summarizes the available literature on the use of parnaparin in different settings of cardiovascular diseases, including papers published during the past year and ongoing studies.
\end{abstract}

Keywords: low-molecular-weight heparin, heparin, parnaparin, acute coronary syndromes, venous thromboembolism

\section{Introduction}

Anticoagulant therapy, such as heparin, has been used for at least 40 years in the management of chronic venous disorders and plays an important role in the prevention and treatment of venous and arterial thrombosis. ${ }^{1}$ Low-molecular-weight heparins (LMWHs) have been extensively investigated in a large number of randomized clinical trials. Where shown to be safe and effective they have been used as drugs for the prevention and treatment of venous thromboembolism (VTE), and for the treatment of acute coronary syndromes (ACS) and peripheral arterial occlusive disease (PAOD), and for the management of chronic venous disorders (CVD), including chronic venous insufficiency (secondary to post-thrombotic syndrome or varicose disease), and varicophlebitis or thrombophlebitis of nonvaricose veins.

Among other LMWHs, parnaparin (parnaparin sodium; Fluxum $\left.{ }^{\mathrm{TM}}\right)^{1}$ has been successfully employed for the prevention and the treatment of VTE and CVD, while its use in the management of ACS and PAOD has been less extensively investigated. ${ }^{2-4}$

The present review focuses on the pharmacological properties and clinical uses of parnaparin, especially in the management of venous thromboembolism, chronic venous disease, PAOD, and coronary artery disease.

\section{Note on dosage}

Dosages of parnaparin reported in this review (3200, 4250, 6400 and 12800 IUaXa) were calculated according to the European Pharmacopea Standard of LMWHs, and (ampence Gampores Unit of Angiology, University Hospital of Padua, Via Giustiniani,

$\mathrm{Tel}+3949-82 / 2838 / 2932 / 2933$

Fax $+3949-8218739$

Email giuseppe.camporese@sanita. padova.it 
are equivalent to those reported in clinical papers published between the early 1980s and the mid 1990s (7500, 10000, 15000 and $30000 \mathrm{aXaU}$, respectively), which in turn were based on the 4th International Standard of Unfractionated Heparin (UFH).

\section{Pharmacology of parnaparin Pharmacodynamics}

Parnaparin is a LMWH with a mean molecular weight of approximately $4.5 \mathrm{kDa}$, obtained with a specific fragmentation procedure that warrants the homogeneity of each fragment in terms of molecular weight and length, in order to optimize and maintain an anti-Xa/anti-IIa ratio of $>4 .^{3,5}$ The pharmacodynamics of subcutaneous parnaparin were investigated in studies in vitro, in healthy volunteers; and in patients with peripheral vascular diseases, acute coronary syndromes and undergoing surgery.

By in vitro studies, parnaparin was shown to possess the following properties:

- inhibition of the thrombin activatable fibrinolytic inhibitor (TAFI) less potently than UFH (with inhibition of $50 \%$ of relative concentrations [IC50] of 0.6 to $0.8 \mathrm{vs} 0.01 \mathrm{U} / \mathrm{mL}$, respectively), similarly to dalteparin and tinzaparin, and more potently than enoxaparin $(\mathrm{IC} 50>1.0 \mathrm{U} / \mathrm{mL}){ }^{6}$

- active control of the anticoagulant effect in the presence of activated platelets, greater than UFH and independent of the concomitant intake of aspirin; ${ }^{7}$

- inhibition of aggregate formation of platelets/ polymorphonuclear leukocytes and of the expression of tissue factor and L-selectin in leukocytes; prevention of leukocyte degranulation and of fibrinogen binding to platelets more potently than UFH and enoxaparin. ${ }^{8,9}$

Studies in healthy volunteers showed that parnaparin inhibits factor Xa (antithrombotic effect) more efficiently than factor IIa (anticoagulant effect), resulting in a greater anti-Xa/ anti-IIa activity ratio than UFH. ${ }^{10-12}$ The inhibition of factor Xa occurs intensively and rapidly (anti-Xa activity about $0.2,0.5$ and $0.9 \mathrm{aXaU} / \mathrm{mL}$, approximatively 2 to 4 hours after administration of parnaparin 3200, 6400 and 12800 IUaXa, respectively), is dose-dependent, and persists for many hours after administration of a single bolus of subcutaneous parnaparin (ranging from 6 to 12 hours after administration of parnaparin 3200 or 6400 IUaXa, with demonstrable anti-Xa activity still occurring at 20 hours with the parnaparin 6400 IUaXa dose; in contrast, the anti-IIa activity was undetectable at 4, 8 and 12 hours postadministration). ${ }^{11}$

Clinical studies conducted in patients undergoing bariatric surgery reported that the obesity (BMI $\geq 45 \mathrm{~kg} / \mathrm{m}^{2}$ ) does not influence parnaparin anti-Xa activity. ${ }^{13}$ When fixed-dose parnaparin is employed as thromboprophylaxis in obese patients, a strong negative correlation between total body weight and anti-factor Xa levels is observed. These findings suggest that weight-based prophylactic dosing might be preferable to fixed-dosing for obese patients, and especially those with severe obesity (BMI $\left.52.4 \mathrm{~kg} / \mathrm{m}^{2}\right) .{ }^{14}$ A similar anti-factor Xa activity inhibitory effect, greater than UFH, is reported both in patients undergoing surgery ${ }^{15-17}$ and in patients with a peripheral arterial occlusive disease (PAOD). ${ }^{18}$ Moreover, in PAOD and surgical patients, as in patients with acute myocardial infarction (MI), parnaparin has been shown to have a weak effect on activated partial thromboplastin time (aPTT) (only the highest dose of 12,800 IU aXa caused a peak value reaching the lower limit of clinical significance), ${ }^{10,11}$ to decrease fibrin formation in a proportional dose-dependent manner, ${ }^{18-20}$ and to reduce whole blood viscosity. ${ }^{20,21}$

Finally, in patients with unstable angina (UA) or acute ST-segment elevation myocardial infarction (STEMI), parnaparin was able to reduce platelet count to a lesser extent than $\mathrm{UFH}^{22,23}$

\section{Pharmacokinetics}

As with other LMWHs, the assessment of the main pharmacokinetic properties after administration of a single dose of parnaparin have been made indirectly ex vivo by measuring anti-Xa activity, considered to be the main antithrombotic mechanism.

In healthy volunteers the peak inhibition of factor $\mathrm{Xa}\left(\mathrm{E}_{\max }\right)$ after subcutaneous administration of parnaparin is dose-dependent $(0.27 \mathrm{IU} / \mathrm{mL}$ after administration of $3200 \mathrm{IUaXa}, 0.58 \mathrm{IU} / \mathrm{mL}$ with $6400 \mathrm{IUaXa}) .{ }^{10-12}$ After intravenous administration $\mathrm{E}_{\max }$ is approximately 5-fold greater than after subcutaneous administration of the same dose (eg, mean $\mathrm{E}_{\max } 1.35 \mathrm{IU} / \mathrm{mL}$ after iv administration of 3200 IUaXa). ${ }^{10,12}$ Parnaparin peak anti-Xa activity $\left(\mathrm{t}_{\max }\right)$ occurs rapidly after administration, approximately 3 hours and 5 minutes when the subcutaneous or intravenous route are used, respectively, regardless of dose. ${ }^{10,12}$ Independently of the injection site (abdomen, gluteal region, deltoid), the bioavailability of the drug was $>90 \% .^{24,25}$ No signs of drug accumulation after repeated once-daily subcutaneous administration for 7 days were detected. ${ }^{26}$

Parnaparin is metabolized in the liver and kidneys and, as with other LMWHs, is cleared principally by the renal route, ${ }^{3}$ however, the effects of renal or hepatic impairment on its pharmacokinetics have not been reported. In general, 
the clearance of the anti-Xa effect of LMWHs is strongly related to the creatinine clearance $(\mathrm{CrCl})$, the cutoff value to avoid accumulation being a $\mathrm{ClCr} \geq 30 \mathrm{~mL} / \mathrm{min}$, and renal insufficiency is associated with an increased risk of bleeding complications when therapeutic doses of LMWHs are used. Conversely, the administration of prophylactic doses is not reported to confer an higher bleeding risk. ${ }^{27}$ Therefore, it is likely that prophylactic doses of parnaparin may be safely administered in patients with severe renal insufficiency; however, if therapeutic doses are needed, weight-adjusted low-doses of parnaparin or UFH (which is not cleared through the kidneys) should be used.,27

\section{Search strategy}

We started with a Medline search, using the keyword "parnaparin" [All Fields], with the limit "human", which yielded 23 papers published between 1993 and 2007, of which 5 were reviews. We also crosschecked the references of all relevant articles and reviews in order to retrieve more evidence. Finally, we asked Alfa Wasserman (Bologna, Italy) to provide us with all the documentation inherent to the clinical development of parnaparin.

\section{Overview of therapeutic efficacy}

Clinical experience with subcutaneous parnaparin in various clinical situations is summarized in Tables 1 to 5 .

\section{Prevention of venous thromboembolic disease (Table I)}

Subcutaneous parnaparin, administered once or twice daily at 3200 or 6400 IuaXa, was compared with placebo ${ }^{28,29}$ or subcutaneous $\mathrm{UFH}^{14-16,30-38}$ in 14 randomized or parallel group studies conducted in adult patients undergoing (major) general, ${ }^{15,28,29,32,34-37}$ orthopedic, ${ }^{16,30,33}$ cardiac, ${ }^{31}$ urologic $^{38}$ and vascular surgery. ${ }^{14}$ Parnaparin was also evaluated in 8 cohort studies ${ }^{22,39-45}$ of patients undergoing (major) general, ${ }^{39}$ vascular, ${ }^{40,41}$ urologic,${ }^{42,43}$ gynecologic,${ }^{44}$ minor orthopedic $^{45}$ and bariatric ${ }^{22}$ surgery, in all of which it was administered once daily at 3200 or $6400 \mathrm{IUaXa}$, but in one $\mathrm{s}^{45}$ at 4250 IUaXa.

Of the studies using a randomized design, $2^{28,29}$ were double-blind placebo-controlled studies, $1^{38}$ was single-blind and the other $7^{14,15,30,31,34,35,37}$ were open, due to different administration schedules. Randomized studies were conducted over $4,{ }^{31} 7,{ }^{14,15,28,29,34,35,37,38}$ or up to $14^{30}$ days; in all parallel group studies, prophylactic treatment with parnaparin lasted for $7^{16,32,33,36}$ days, and in cohort studies for $7,{ }^{39,42-44} 8,{ }^{41}$ $9,{ }^{40} 10^{45}$ and $30^{22}$ days. Prophylactic therapy was generally initiated 2 hours before low- to medium-risk thromboembolic surgery, and 12 hours before high-risk surgery. In a cohort study of patients undergoing minor orthopedic procedures, parnaparin was initiated 3 to 9 hours postoperatively. ${ }^{45}$

The efficacy endpoints were: frequency of DVT, investigated with venography, ultrasonography (continuous-wave Doppler, compression ultrasound, color-coded Doppler ultrasound), fibrinogen uptake test or plethysmography (impedance, strain-gauge); and the frequency of pulmonary embolism (PE), which was assessed with ventilation/perfusion lung scan or chest X-ray, if suspected on clinical grounds (Table 1).

In general, although the methodological quality of the trials published before 1990 was modest, subcutaneous parnaparin demonstrated to be effective in the prevention of DVT and PE (Table 1). Specifically, subcutaneous parnaparin was at least as effective as UFH in preventing DVT across all clinical trials; and in two large studies in patients undergoing general surgery $(n=610$, and $n=173$, respectively), ${ }^{32,35}$ the incidence of DVT in the parnaparin (3200 or 6400 IUaXa once-daily) group was statistically significantly lower than in the UFH (5000 IU 2- or 3-times daily) group $(3.2 \%$ vs $6.3 \%, P<0.05$; and $1.1 \%$ vs $7.1 \%$, $P=0.038$, respectively).

The low number of events recorded did not allow meaningful statistical comparisons for the frequency of PE.

\section{Treatment of deep-vein thrombosis (Table 2)}

Subcutaneous parnaparin, administered once or twice daily at 6400 or 12,800 IuaXa, was compared with intravenous ${ }^{46}$ or subcutaneous ${ }^{47,48} \mathrm{UFH}$, or with nadroparin ${ }^{49}$ in 4 randomized trials of adult patients with objectively proven DVT. In all studies parnaparin was at least as effective as the comparator in preventing recurrent extending DVT and PE, with a similar safety profile. The short duration of patient observation (at most 6 months), combined with the choice of noninvasive tests to assess the endpoints (frequency of recurrent/extending DVT, and frequency of PE) is very likely responsible for the low frequency of events observed.

\section{Chronic venous disease (Table 3)}

The efficacy of parnaparin in the treatment of postphlebitic syndrome or chronic venous insufficiency of the lower limbs was compared with that of UFH in 5 randomized trials. ${ }^{51-55}$ Treatment duration ranged from 30 to 90 days. These small-sample (number of patients included $=46$ to 92 ) 


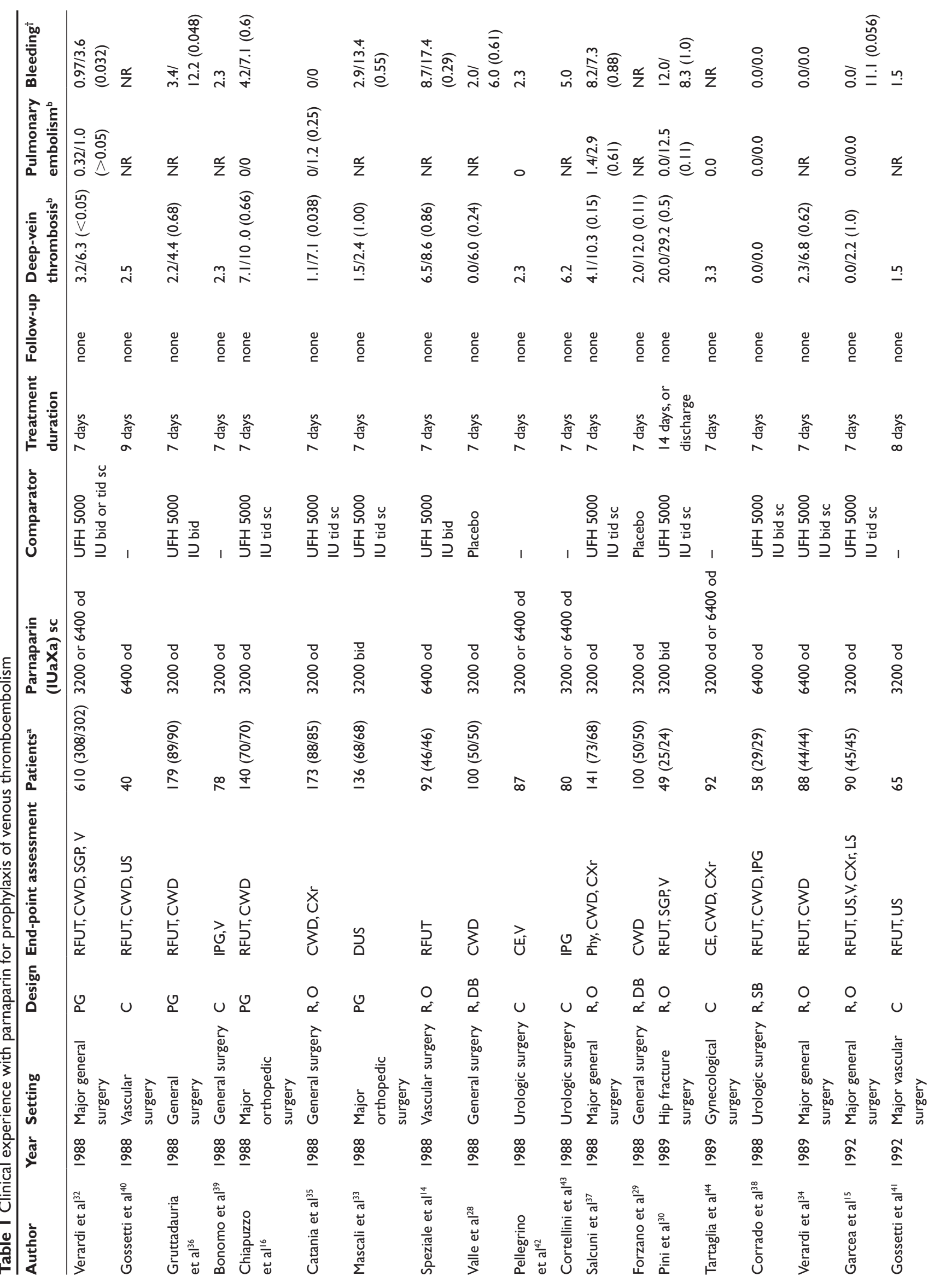




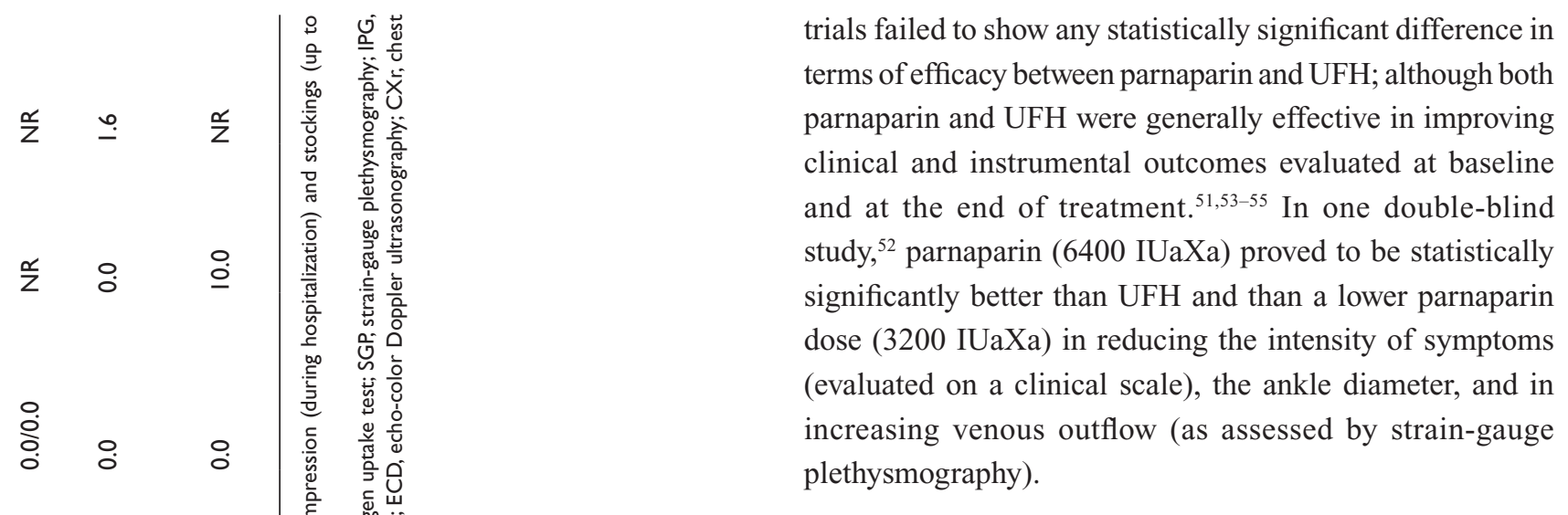

\section{Peripheral arterial occlusive disease (Table 4)}

Subcutaneous parnaparin (6400 IUaXa once-daily) was compared with placebo in 6 small (number of patients $=33$ to 36) randomized trials ${ }^{56-61}$ or with UFH in one nonrandomized study, ${ }^{13}$ performed over $6^{56-61}$ or $7^{13}$ months. All randomized studies, except one ${ }^{58}$ were double-blinded, and conducted in patients with stage II disease (Leriche-Fontaine classification). Endpoints included the evaluation of pain-free walking distance (by treadmill) or time of rest and peak calf blood flow (by strain-gauge plethysmography), and of the ankle-brachial index (ratio between ankle and brachial artery pressures, normal ratio being $>0.9$ ).

In 4 of these studies ${ }^{56,58-60}$ parnaparin significantly improved pain-free walking distance or time, ankle-brachial index, or both, as compared to placebo. In the remaining 3 studies, ${ }^{13,57,61}$ in which only within-group analysis was available, baseline values for pain-free walking distance, blood flow, or ankle-brachial index were significantly increased at the end of the treatment period in the parnaparin group $^{57}$ or in both parnaparin and the $\mathrm{UFH}^{13}$ or placebo ${ }^{61}$ groups, respectively.

\section{Acute coronary syndromes (Table 5)}

Parnaparin was compared with placebo in a small $(n=29)$, randomized, double-blind study of patients with stable angina, ${ }^{62}$ and with UFH in 2 large-sample randomized nonblinded trials of patients with unstable angina ${ }^{21}$ and STEMI. ${ }^{23}$

The two larger trials ${ }^{21,23}$ used composite efficacy hard endpoints, including death, while the smaller used only substitute endpoints. ${ }^{62}$ In the two larger trials, parnaparin yielded a statistically significant reduction in the frequency of the primary efficacy endpoint versus $\mathrm{UFH},{ }^{21,23}$ while in the smaller trial a statistically significant improvement in the primary efficacy endpoint was observed only in the 


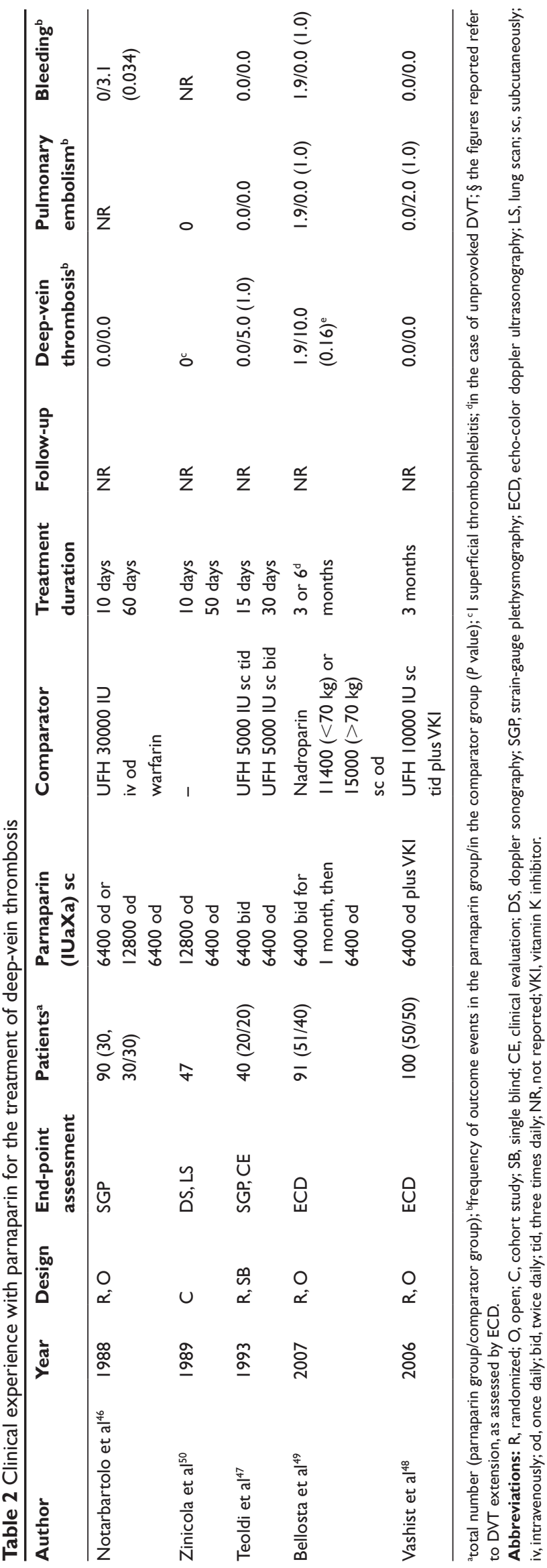

parnaparin group (no between-group comparisons available) versus placebo. ${ }^{62}$

\section{Clinical update}

Based on our search strategy, we were able to retrieve 1 full paper, ${ }^{63}$ and 2 congress abstracts ${ }^{64,65}$ dealing with clinical uses of parnaparin which were published during 2008. The first, a small-sample $(n=10)$ open-label study, ${ }^{63}$ evaluated the efficacy of 3 different oral dosages (70, 140 and $210 \mathrm{mg}$ once daily) of parnaparin in the treatment of mild-to-moderate relapse of left-sided ulcerative colitis, over 8 weeks. The endpoints were standardized clinical and endoscopic activity of the disease. At the end of the treatment, 7 patients (70\%) were in clinical remission, only 1 achieving endoscopic healing, and standardized clinical scores were statistically significantly improved from baseline. The second, a randomized open multicenter dose-finding study of patients $(n=66)$ with severe obesity (BMI > 36) undergoing bariatric surgery, evaluated the effect of 2 parnaparin doses (4250 IUaXa or 6400 IUaXa, administered once daily for $9 \pm 2$ days) on anti-Xa levels, evaluated the day before operation, and at 4 and at 6 days after operation. The authors observed that with the administration of 4250 IUaXa the anti-Xa levels were within the expected activity range in $98.3 \%$ of the cases, while with $6400 \mathrm{IUaXa}$ the anti-Xa activity was above the specified prophylactic range in 62.3 of the cases. ${ }^{64}$ The third study reported the results of a multicenter, randomized, double-blind, controlled trial comparing the efficacy and safety of aspirin $(100 \mathrm{mg} /$ daily for 3 months) versus parnaparin $(12,800 \mathrm{IUaXa}$ for 7 days followed by 6400 IUaXa for a total of 3 months) for treatment of retinal vein occlusion (RVO). The primary efficacy endpoint of the study was the incidence of functional worsening of the eye with RVO at 6 months, objectively assessed by fluorescein angiography, visual acuity and visual field. The endpoint was adjudicated in $20.7 \%$ of patients treated with parnaparin $(\mathrm{n}=28)$ and in $59.4 \%$ of patients treated with aspirin $(\mathrm{n}=30)(P=0.002)$. Recurrent RVO was diagnosed in 3 patients, all treated with aspirin $(P=\mathrm{ns})$. Bleeding rates were similar between the two groups. Due to the small sample size of patients, the authors concluded that these promising results need to be confirmed in a larger clinical trial. ${ }^{65}$

No clinical studies using parnaparin during 2009 were retrieved, but we are aware of an ongoing phase 3 Italian multicenter randomized clinical trial (STEFLUX trial, all active recruiting centers located in Italy) on the treatment of superficial thrombophlebitis. The study compares the efficacy and safety of 3 different doses of parnaparin (8500 IUaXa subcutaneous, once daily for 


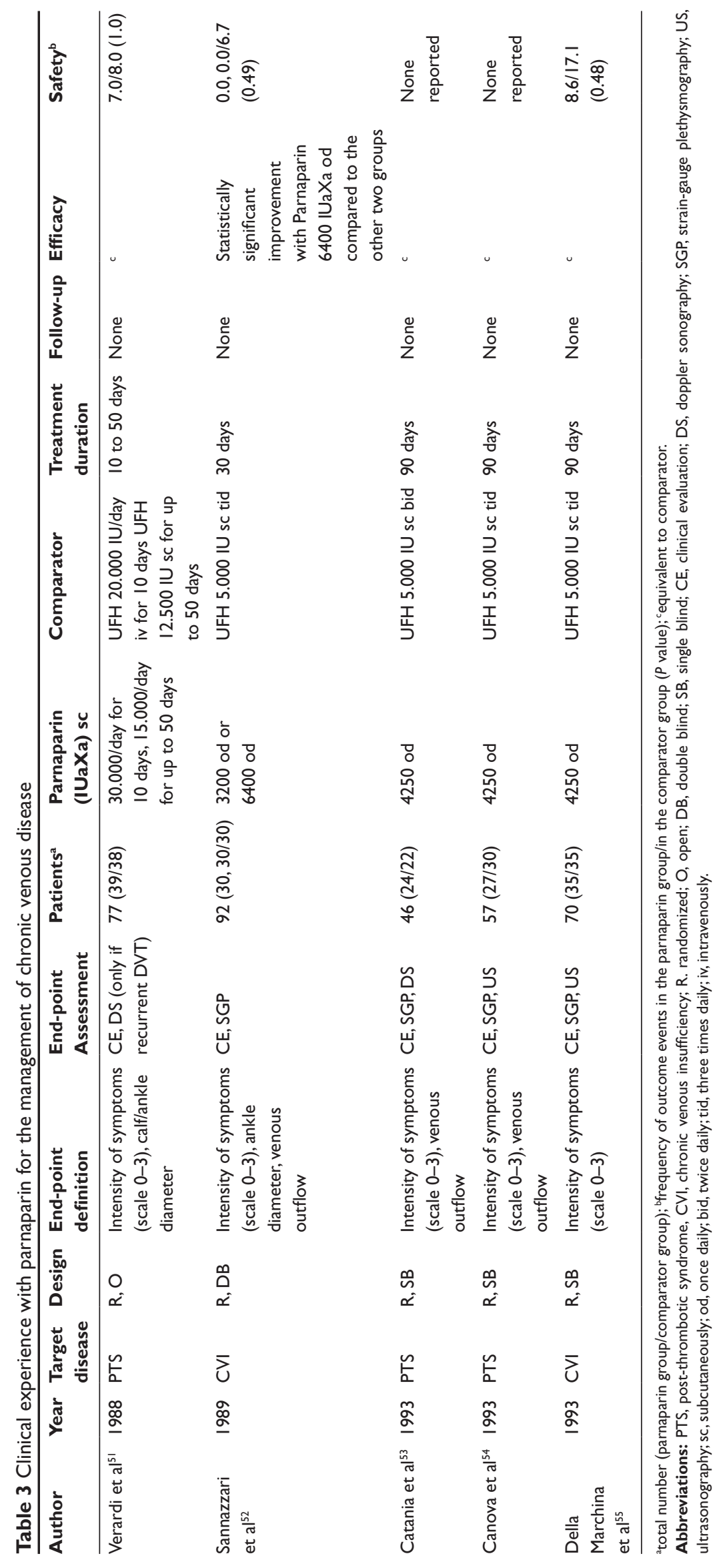




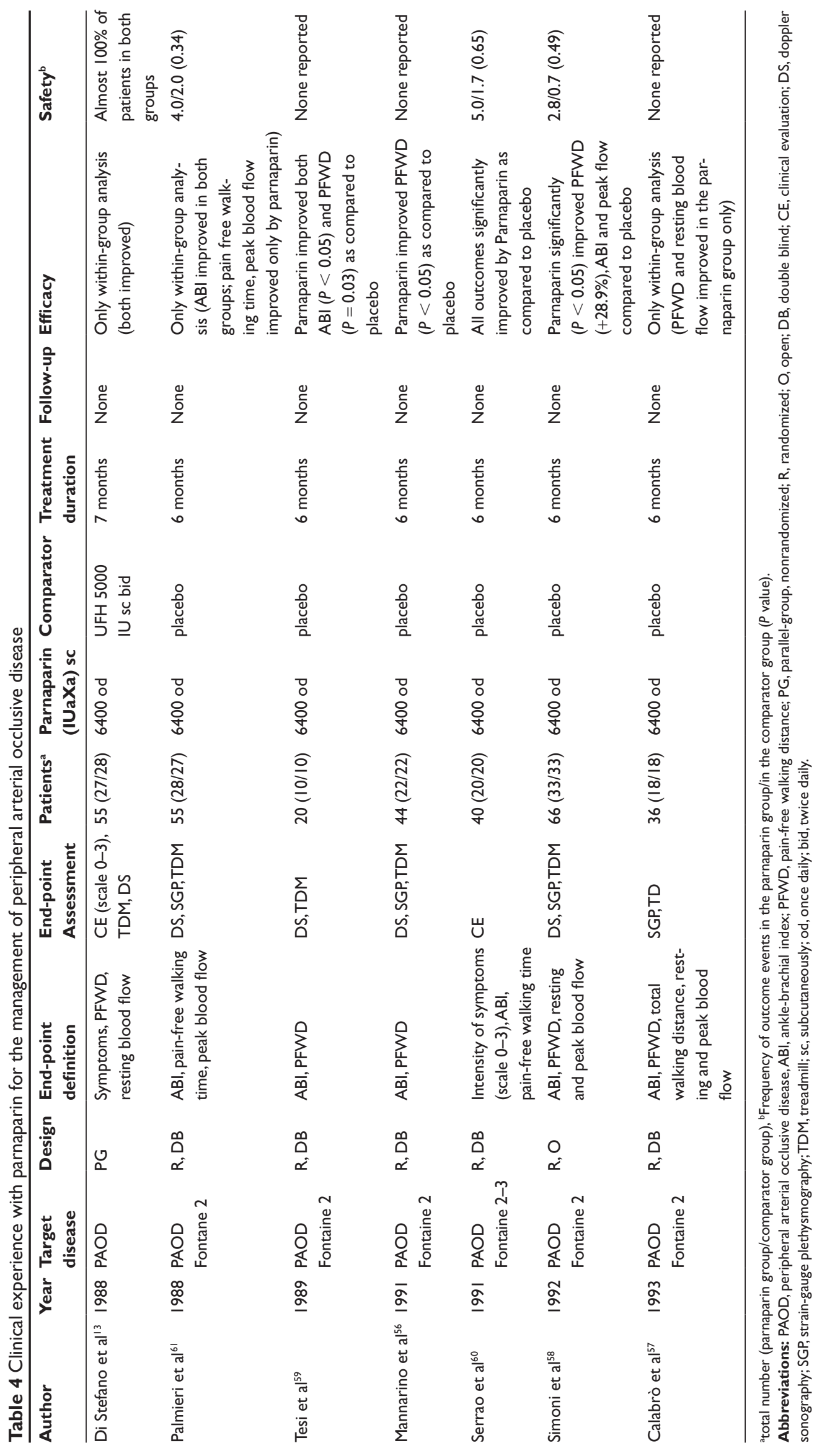




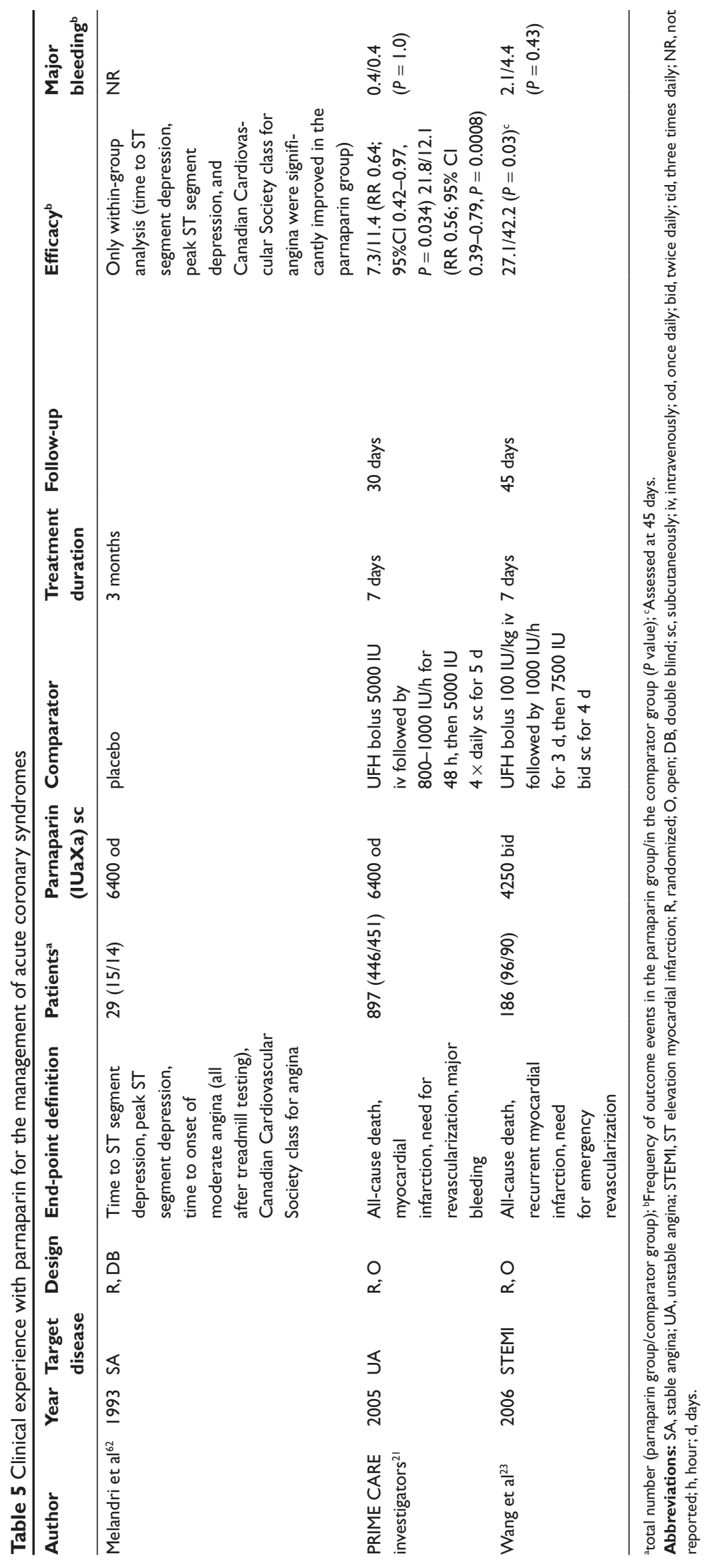


10 days followed by placebo for 20 days versus $8500 \mathrm{IUaXa}$ subcutaneous, once daily for 10 days, followed by 6400 IUaXa subcutaneous, once daily for 20 days; versus 4250 IUaXa subcutaneous, once daily for 30 days), and the planned sample size exceeds 1000 patients.

\section{Tolerability and management}

In all clinical trials in which parnaparin was investigated, a general good tolerability was reported. As with the other commercially available LMWHs, the most important side effect was bleeding, usually classified as major (heavy blood loss, such as clinically overt hemorrhage associated with hemoglobin drop of at least $2 \mathrm{~g} / \mathrm{L}$ or requiring the transfusion of 2 or more units of packed redblood cells; or bleeding at life-threatening sites, such as retroperitonal or intracranial events; or bleeding requiring re-intervention) or minor (including, for example, bleeding at the injection site). ${ }^{21,23}$ Studies of thromboprophylaxis after major surgery reported of an incidence of hemorrhagic complications ranging from $1 \%$ to $4 \%$, whereas in studies dealing with parnaparin use in unstable angina, a $3 \%$ incidence of minor bleeding and only 1 major bleeding were observed. ${ }^{15,21,28,32}$ In a study considering patients with STEMI, bleedings events occurred in 3\% of patients receiving parnaparin. ${ }^{23}$ After minor orthopedic surgery, bleeding complications were reported in $<2 \%$ of the 509 patients investigated, most of which were minor bleedings (injection site hematomas). ${ }^{45}$

In studies evaluating the use of parnaparin in peripheral vascular diseases or chronic venous disorders, minor bleeding complications and/or pain occurred less in patients allocated to subcutaneous parnaparin than in those randomized to subcutaneous UFH. ${ }^{13,32,55,66}$
Heparin-induced thrombocytopenia (HIT) is another well known complication of heparin, its incidence being approximately $0.8 \%$, with LMWH, about 3 -fold lower than with UFH. ${ }^{67,68}$ HIT is caused by heparindependent antibodies (usually immunoglobulin G) binding a confirmationally modified epitope on platelet factor 4 (PF4), its modified structure being subsequently recognized as a foreign protein by the immunocompetent cells of the patients. HIT was not observed in any of the clinical trials of parnaparin discussed in this review. Nonetheless, patients receiving either a prophylactic or a therapeutic course of parnaparin are recommended to carefully monitor their platelet count during the first 2 weeks of exposure to the drug, especially those with a recent history of heparin exposure, who are at higher risk of developing HIT. ${ }^{5}$

Parnaparin is administered at different dosage according to the type and the severity of the disease. Doses and administration of parnaparin in different clinical settings are shown in Table 6. Caution should be used in patients with renal or hepatic insufficiency, arterial hypertension, or any organ lesion subject to bleeding. ${ }^{5}$

\section{Place in therapy and conclusion}

In VTE prevention, parnaparin administered subcutaneously (3200 UIaXa) once daily for 7 days showed to be more effective than placebo ( $0 \%$ versus $6 \%$, respectively) and at least as effective as UFH, in patients undergoing abdominal, vascular, orthopedic (major and minor) or cardiac surgery.

Compared to UFH, the equivalent efficacy of parnaparin given once daily for up to 3 months has been demonstrated in the treatment of CVD (above all chronic venous insufficiency secondary to a post-thrombotic syndrome), superficial trombophlebitis and DVT.

Table 6 Dosage and administration of parnaparin in different clinical settings

\begin{tabular}{lll}
\hline Setting & Dose, UlaXa & Route and frequency \\
\hline Treatment of CVD, SVT, VPH & 3200 to 6400 & sbc, od for 20-30 d \\
DVT prevention in general nonhigh risk surgery & 3200 & sbc, od $2 \mathrm{~h}$ before surgery, then for at least $7 \mathrm{~d}$ \\
DVT prevention in general high risk surgery, or orthopedic & 4250 & sbc, od I2 h before surgery I2 h after surgery, \\
surgery & 12800 & at least for 10 \\
DVT treatment & 6400 & iv slow, for 3-5 d sbc, \\
& $4250-6400$ & tid for at least 7-10 d sbc, \\
Unstable angina & 6400 & od for 10-20 d \\
STEMI & 4250 & sbc, od for $7 \mathrm{~d}$ \\
PAOD & 6400 & sbc, tid for $7 \mathrm{~d}$ \\
\hline
\end{tabular}

Abbreviations: CVD, chronic venous diseases; SVT, superficial vein thrombophlebitis; VPH, varicophlebitis; DVT, deep vein thrombosis; STEMI, ST-segment elevation myocardial infarction; PAOD, peripheral arterial occlusive disease; sbc, subcutaneous; od, once-daily; tid, twice-daily; d, days; m, months. 
In patients with stable angina a 3-month course of therapy with parnaparin provides a significant improvement in the exercise time on treadmill test compared with baseline, but not in patients receiving placebo. Recently, in patients with unstable angina or STEMI, once-daily subcutaneous parnaparin has been shown to be able to significantly reduce the primary efficacy composite endpoint of death, acute MI or need for emergency myocardial revascularization (including coronary artery bypass grafting or angioplasty) in the first 7 days or 45 days after the start of treatment, respectively, compared to UFH (7\% vs $11 \%$, $P=0.034 ; 27 \%$ vs $42 \%, P=0.03$, respectively).

Subcutaneous parnaparin has been compared with placebo or UFH in patients with stage II PAOD (Leriche-Fontaine Classification). Compared with both placebo or UFH, parnaparin was able to significantly improve all the endpoints investigated, such as pain-free walking time and painfree walking distance, peak blood flow in the calf and the ankle-brachial index.

Tolerability of parnaparin has been generally reported across all studies. The risk of bleeding complications arising from parnaparin compared with UFH seems similar for the major bleeds, whereas the incidence of minor bleeds is lower with parnaparin.

No cases of HIT are reported with parnaparin use. However, a platelet count should be taken every 3 days for the first 2 weeks of treatment in all patients receiving parnaparin.

As with other LMWHs, and in contrast to UFH, parnaparin enables patients with most peripheral vascular diseases to be treated at home or as an outpatient because treatment is easy to manage, has good tolerability, equivalent efficacy and safety.

Further applications of parnaparin have been recently investigated in different settings (ulcerative colitis, RVO, severe obese patients undergoing bariatric surgery), even though its promising results on efficacy need to be confirmed in larger clinical trials.

In conclusion, parnaparin is a safe, effective, well tolerated LMWH widely investigated and used in the prevention and treatment of VTE, and in the management of CVD and of coronary artery disease. As with other LMWHs, parnaparin can be administered subcutaneously, once daily, with a better local tolerability than UFH, and the available data indicate that parnaparin could be the optimal choice among all the commercially available LMWHs.

\section{Disclosures}

The authors declare no conflicts of interest.

\section{References}

1. Alexander JH, Singh KP. Inhibition of factor Xa: a potential target for the development of new anticoagulants. Am J Cardiovasc Drugs. 2005;5(5):279-290.

2. Dettori AG. Parnaparin: a review of its pharmacological profile and clinical application. Drugs Today. 1995;31(1):19-35.

3. Frampton JE, Faulds D. Parnaparin: a review of its pharmacology, and clinical application in the prevention and treatment of thromboembolic and other vascular disorders. Drugs. 1994;47(4):652-676.

4. McKeage K, Keating GM. Parnaparin, A review of its use in the management of venous thromboembolism, chronic venous disease and other vascular disorders. Drugs. 2008;68(1):105-122.

5. Fluxum ${ }^{\mathrm{TM}}$. Summary of product characteristics. Bologna: Alfa Wassermann, 2007.

6. Maugeri N, de Gaetano G, Barbanti M, et al. Prevention of platelet-polymorphonuclear leukocyte interactions: new clues to the antithrombotic properties of parnaparin, a low molecular weight heparin. Haematologica. 2005;90(6):833-839.

7. Maugeri N, Di Fabio G, Barbanti M, et al. Parnaparin, a low- molecular-weight heparin, prevents P-select-independent formation of platelet-leukocyte aggregates in human whole blood. Thromb Haemost. 2007;97(6):965-973.

8. Melandri G, Semprini F, Cervi V, et al. Comparison of efficacy of low molecular weight heparin (parnaparin) with that of unfractionated heparin in the presence of activated platelets in healthy subjects. $A m J$ Cardiol. 1993;72(5):450-454.

9. Florian-Kujawski M, Hoppensteadt D, Maddineni J, et al. Differential regulation of thrombin activatable fibrinolytic inhibitor by low molecular weight heparins: pharmacologic implications. Int Angiol. 2004;23(4):346-354.

10. Verhaeghe R. The use of low-molecular-weight heparins in cardiovascular disease. Acta Cardiol. 1998;53(1):15-21.

11. Palareti G, Legnani C, Bianchini B, et al. Pharmacodynamic effects on blood coagulation of a new low molecular weight heparin (alfa-LMWH) in healthy volunteers and gynecologic surgery patients. Int Angiol. 1989;8(1):47-52.

12. Dettori AG, Tagliaferri A, Dall'Aglio E, et al. Clinical pharmacology of a new low molecular weight heparin (alfa LMWH- Fluxum). Int Angiol. 1988;7(3 Suppl):7-18.

13. Di Stefano F, Giglio A, Vinci M, et al. Low molecular weight heparins for long-term therapy of peripheral vascular disease. Curr Ther Res. 1988;44(1):1-10.

14. Speziale F, Verardi S, Taurino M, et al. Low molecular weight heparin prevention of post-operative deep vein thrombosis in vascular surgery. Pharmatherapeutica. 1988;5(4):261-268.

15. Garcea D, Martuzzi F, Santelmo N, et al. Post-surgical deep vein thrombosis prevention: evaluation of the risk/benefit ratio of fractionated and unfractionated heparin. Curr Med Res Opin. 1992;12(9): $572-583$.

16. Chiapuzzo E, Orengo GB, Ottria G, et al. The use of low molecular weight heparins for post-surgical deep vein thrombosis prevention in orthopaedic patients. J Int Med Res. 1988;16(5):359-366.

17. Legnani C, Imberti D, Cini M, et al. Pharmacodynamic of low molecular weight heparin (LMWH) in obese subjects undergoing bariatric surgery: a prospective randomised study comparing two different doses of parnaparin [abstract no. P153] Haematologica. 2006; 91 Suppl 2:89. Plus poster presented a the XIX Congress of the Italian Society for Studies on Hemostasis and Thrombosis; 2006 Sep 14-17: Milan.

18. Melandri G, Branzi A, Semprini F, et al. Effects of two dosages of subcutaneous low molecular weight heparin (parnaparin) and of unfractionated heparin on fibrin formation and lipolysis in acute myocardial infarction. Thromb Res. 1992;66(2-3):141-150.

19. Mannarino E, Pasqualini L, Innocente S, et al. Efficacy of low- molecular-weight heparin in the management of intermittent claudication. Angiology. 1991;42(1):1-7. 
20. Calabrò A, Piarulli F, Milan D, et al. Clinical assessment of low molecular weight heparin effects in peripheral vascular disease. Angiology. 1993;44(3):188-195.

21. PRIME CARE Study Investigators Group. Comparative efficacy of once daily parnaparin and unfractionated heparin in unstable angina pectoris: PRIME CARE study. Indian Heart J. 2005;57(6):648-654.

22. Forestieri P, Quarto G, De Caterina M, et al. Prophylaxis of thromboembolism in bariatric surgery with parnaparin. Obes Surg. 2007;17(12):1558-1562.

23. Wang XK, Zhang Y, Yang CM, et al. Use of unfractionated heparin and a low-molecular-weight heparin following thrombolytic therapy for acute ST-segment elevation myocardial infarction. Clin Drug Invest. 2006;26(6):341-349.

24. Wong GC, Giugliano RP. Low-molecular-weight heparins for the treatment of acute coronary syndromes. Semin Vasc Med. 2003;3(4):391-402.

25. Dettori AG, Babbini M. Human pharmacology of a low-molecular-weight heparin (alfa-LMWH): an update. Med Res Rev. 1992;12(4):373-389.

26. Agrati AM, Ambrosi G, Spinelli G, et al. Influence of the administration site on the bioavailability of a new low molecular weight heparin administered by subcutaneous route. Aggiornamenti di Medicina e Chirurgia. 1991;9(3):375-379.

27. Palmieri GC, Ambrosi G, Ferrero G. Kinetic control in healthy volunteers of low molecular weight heparin antithrombotic activity. Riv Eur Sci Med Farmacol. 1988;10:187-192.

28. Valle I, Sola G, Origone A. Controlled clinical study of the efficacy of a new low molecular weight heparin administered subcutaneously to prevent postoperative deep venous thrombosis. Curr Med Res Opin. 1988;11(2):80-86.

29. Forzano F, Nicora E. Assessment of efficacy and tolerance of a new low molecular weight heparin in post-operative thromboembolic prophylaxis. Aggior Med Chir. 1989;7:1-9.

30. Pini M, Tagliaferri A, Manotti C, et al. Low molecular weight heparin (alfa LHWH) compared with unfractionated heparin in prevention of deep-vein thrombosis after hip fractures. Int Angiol. 1989;8(3):134-139.

31. Beghi C, Fragnito C, Antonelli A, et al. Prevention of deep venous thrombosis by a new low molecular weight heparin (Fluxum) in cardiac surgery. Int Angiol. 1993;12(4):383-386.

32. Verardi S, Casciani CU, Nicora E, et al. A multicentre study on LMW-heparin effectiveness in preventing postsurgical thrombosis. Int Angiol. 1988;7(3 Suppl):19-24.

33. Mascali F, Condorelli A, Salanitiri G, et al. Postsurgery thromboembolism prevention by LMW heparin subcutaneous administration. Eur Rev Med Pharmacol Sci. 1988;10:135-141.

34. Verardi F, Cortese F, Baroni B. Deep vein thrombosis prevention in surgical patients: effectiveness and safety of a new a low molecular weight heparin. Curr Ther Res. 1989;46:366-372.

35. Catania G, Salanitri G. Prevention of postoperative deep vein thrombosis by two different heparin types. Int J Clin Pharmacol. 1988;26: 304-309.

36. Gruttadauria G, Ferrara C, Musumeci S. Subcutaneous low-molecular weight heparin for postsurgical thromboembolism prevention. Med Praxis. 1988;9(4):1-9.

37. Salcuni PF, Azzarone M, Palazzini E. A new low molecular weight heparin for deep vein thrombosis prevention: effectiveness in postoperative patients. Curr Ther Res. 1988;43:824-831.

38. Corrado F, Fini M, Severini G, et al. Low-molecular weight heparin (Fluxum) prevention of post-operative thrombosis in urological surgery. A controlled study. Clin Trials J. 1988;26:138-148.

39. Bonomo GM, Scattarella M, Treglia AL. Preventing postsurgery thromboembolism by a new low molecular weight heparin. Med Praxis. 1988;9(4):1-7.

40. Gossetti B, Irace L, Gattuso R, et al. Prevention of deep venous thrombosis in vascular surgical procedures by LMW-heparin. Inter Angio. 1988;7 Suppl 3:25-27.
41. Gossetti B, Irace L, Venosi S, et al. Low-molecular weight heparin in prevention of deep vein thrombosis prevention in major vascular surgery. Phlébologie. 1992;92:456-458.

42. Pellegrino A, BAlta D, De Girolamo C, et al. Prevention of post-surgical deep vein thrombosis in urology. Prophylactic use of a new low molecular weight heparin. Clinical Trials Journal. 1988;25:164-171.

43. Cortellini P, Pelletti F, Simonazzi M.P, et al. Prevention of post-operative thromboembolism. A clinical trial in urological patients treated with a new low molecular weight heparin. Acta Ther. 1988;14:135-144.

44. Tartaglia P, Perolo F, D'Ales A. Effectiveness of prevention with a low molecular weight heparin preparation in gynecological patients undergoing surgery: an open study. Curr Med Res Opin. 1989;11(6):360-365.

45. Montebugnoli M, Bugamelli S, Calo P, et al. Prophylaxis of venous thromboembolism in minor orthopedic surgery with parnaparin. Clin Appl Thromb Hemost. 2007;13(3):249-258.

46. Notarbartolo A, Salanitri G, Davì G, Averna M, Barbagallo C, Catalano I. Low-molecular weight heparin in the short and long-term treatment of deep vein thrombosis in diabetic subjects. Med Praxis. 1988;9(4):1-13.

47. Teoldi A, Botticella F, Maloberti MR. Antithrombophilic effect of low molecular weight heparins in patients with deep vein thrombosis. Clinical Trials Metaanal. 1993;28:215-225.

48. Vashist MG, Kapoor S, Dhingra A, et al. Is low molecular weight heparin effective and safe in the management of deep vein thrombosis? A prospective randomized study. Ind Med Gaz. 2006;140:175-178.

49. Bellosta R, Ferrari P, Luzzani L, et al. Home therapy with LMWH in deep vein thrombosis: randomized study comparing single and double daily administrations. Angiology. 2007;58(3):316-322.

50. Zinicola N, Cerruti R. Deep vein thrombosis of the lower limbs: results of long term treatment with a new low-molecular weight heparin. Farmaci e terapia. 1989;3:147-151.

51. Verardi S, Ippoliti A, Pistolese GR. Antithrombotic treatment during acute inflammatory complications of patients affected by postphlebytic syndrome: LMW-heparin versus standard heparin. Int Angiol. 1988;7 Suppl 3:33-40.

52. Sannazzari P. Low molecular weight heparin in the symptomatic treatment of chronic venous insufficiency: controlled double blind study vs calcium heparin. Panminerva Med. 1989;31(3):127-133.

53. Catania G, Salanitri T. Heparin therapy of post-phlebitic syndrome: results of a single-blind, clinical trial of parnaparin vs calcium heparin. Stampa Medica Europea. 1993;13:17-27.

54. Canova R, Celentano R, Gasbarrone L. Long-term treatment of patients with post-phlebitic syndrome by means of a new lmw heparin. NAM. 1993;9:318-324.

55. Della Marchina M, Renzi G, Renzi C, et al. Low molecular weight heparins in chronic venous insufficiency: controlled trial of parnaparin efficacy and tolerability. Br J Clin Res. 1993;4:29-36.

56. Mannarino E, Pasqualini L, Innocente S, et al. Efficacy of low- molecular-weight heparin in the management of intermittent claudication. Angiology. 1991;42(1):1-7.

57. Calabrò A, Piarulli F, Milan D, et al. Clinical assessment of low molecular weight heparin effects in peripheral vascular disease. Angiology. 1993;44(3):188-195.

58. Simoni G, Lucertini G, Decian F. Low molecular weight heparins: therapeutic insight in peripheral arterial occlusive disease. Clin Trials Metaanal. 1993;28:137-145.

59. Tesi M, Bronchi GM, CArini A, et al. Efficacy and safety of a new low-molecular weight heparin in the medium-term treatment of atherosclerotic arteriopathy of the lower limbs. J Drug Dev. 1989;2:73-82.

60. Serrao E, Mangialardi N. Treatment of peripheral arteriopathies with a new low weight heparin. Panminerva Medica. 1991;33:197-204.

61. Palmieri G, Ambrosi G, Agrati AM, et al. A new low molecular weight heparin in the treatment of peripheral arterial disease. Int Angiol. 1988;7 Suppl 3:41-47.

62. Melandri G, Semprini F, Cervi V, et al. Benefit of adding low molecular weight heparin to the conventional treatment of stable angina pectoris: a double-blind, randomized, placebo- controlled trial. Circulation. 1993;88:2517-2523. 
63. Pastorelli L, Saibeni S, Spina L, et al. Oral, colonic-release low-molecular-weight heparin: an initial open study of ParnaparinMMX for the treatment of mild-to-moderate left-sided ulcerative colitis. Aliment Pharmacol Ther. 2008;28(5):581-588.

64. Imberti D, Baldini E, Nicolini A, et al. Farmacodinamica dell'eparina a basso peso molecolare in pazienti sottoposti a intervento di chirurgia bariatrica: studio prospettico randomizzato tra due differenti dosi di parnaparin (studio BAFLUX). Atti XVI Congresso Nazionale SICOB; 2008.

65. Ageno W, Cattaneo R, Manfredi E, et al. Parnaparin versus aspirin in the treatment of retinal vein occlusion. A randomized, double blind, controlled study. Atti XX Congresso Nazionale della Società Italiana per lo Studio dell'Emostasi e della Trombosi (SISET), Firenze, 2008. Haematologica. 2008;93 Suppl 3:33:CO98.

66. Luttichau U, Palazzini E. Antithrombotic therapy in phlebopathies of lower limbs: a controlled study of low molecular weight heparin versus heparin calcium. Eur Rev Med Pharmacol Sci. 1989;11:351-358.
67. Warkentin TE, Levine MN, Hirsh J, et al. Heparin-induced thrombocytopenia in patients treated with low-molecular- weight heparin or unfractionated heparin. N Engl J Med. 1995;332(20): 1330-1335.

68. Prandoni P, Siragusa S, Girolami B, et al. The incidence of heparininduced thrombocytopenia in medical patients treated with lowmolecular-weight heparin: a prospective cohort study. Blood. 2005;106(9):3049-3054.

69. Geerts WH, Pineo GF, Heit JA, et al. Prevention of venous thromboembolism: the Eightieth ACCP Conference on Anti- thrombotic and Thrombolytic Therapy. Chest. 2008;133(6 Suppl):381S-453S.

70. Baglin T, Barrowcliffe TW, Cohen A, et al. Guidelines on the use and monitoring of heparin. The British Committee for Standards in Haematology. Br J Haematol. 2006;133(1):19-34.
Vascular Health and Risk Management

\section{Publish your work in this journal}

Vascular Health and Risk Management is an international, peerreviewed journal of therapeutics and risk management, focusing on concise rapid reporting of clinical studies on the processes involved in the maintenance of vascular health; the monitoring, prevention and treatment of vascular disease and its sequelae; and the involvement of

\section{Dovepress}

metabolic disorders, particularly diabetes. This journal is indexed on PubMed Central and MedLine. The manuscript management system is completely online and includes a very quick and fair peer-review system, which is all easy to use. Visit http://www.dovepress.com/ testimonials.php to read real quotes from published authors. 